\title{
Dexamethasone and COVID-19 in a Developing Country: Appropriate Use?
}

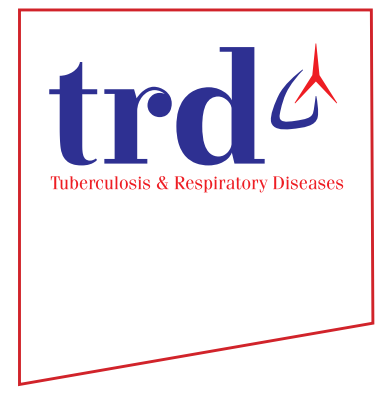

\author{
Diego Martin Moreno Marreros, B.Med. ${ }^{1}{ }^{(0)}$, Maycol Leonardo Aburto Moreno, B.Med. ${ }^{2}$, Kattia $^{2}$ \\ Gassely Torres Gil, B.Med. ${ }^{1}$ and Carlos Morera Guzman, B.Med. ${ }^{1}$ \\ ${ }^{1}$ Division of Internal Medicine, Hospital II Chocope-EsSalud, Ascope, ${ }^{2}$ Division of Internal Medicine, Hospital de Alta \\ Complejidad Virgen de la Puerta, Trujillo, Peru
}

We have carefully read the publication by Lee et al. ${ }^{1}$ wherein they state that patients who receive dexamethasone in the first 24 hours of presenting $\mathrm{SpO}_{2}<90 \%$ at $\mathrm{FiO}_{2} 21 \%$ have a lower risk of severe coronavirus disease 2019 (COVID-19), defined as the use of a high-flow nasal cannula or mechanical ventilation, than in the control group ( $75.9 \%$ vs. $40.0 \%, \mathrm{p}=0.012)$ in addition to fewer days of supplemental oxygen ( 10.45 days vs. 21.61 days, $\mathrm{p}=0.003)$ and length of stay in the hospital (19.76 days vs. 27.21 days, $\mathrm{p}=0.013)^{1}$.

The use of dexamethasone in patients receiving oxygen therapy is widely applied in the management of patients with COVID-19. In the study carried out by the RECOVERY trial, a decrease in mortality was observed at 28 days after the treatment with dexamethasone at a dose of $6 \mathrm{mg}$ /day for up to 10 days, regardless of the oxygen support device ${ }^{2}$. However, other studies suggest that the impact on mortality may vary according to the type of device used for oxygen therapy. Bahl et al. ${ }^{3}$ stated that there is a reduced risk of mortality in patients on mechanical ventilation (hazard ratio [HR], 0.38 ; $95 \%$ confidence interval $[\mathrm{CI}], 0.24-0.60 ; \mathrm{p}<0.001)$ but not in patients with high-flow or other oxygen therapy (HR, 0.46; 95\% CI, $0.20-1.07 ; \mathrm{p}=0.07$ and HR, 0.84; 95\% CI, 0.35-2.00; $\mathrm{p}=0.69$ ), respectively.

Although it is true that dexamethasone has a beneficial effect, it can have harmful effects such as hyperglycemia, blurred

Address for correspondence: Diego Martin Moreno Marreros, B.Med.

Division of Internal Medicine, Hospital II Chocope-EsSalud, Fco

Adrianzen 312, Urb Santa Maria V Etapa, Trujillo, Peru

Phone: 51-950291202, Fax: 51-044-678821

E-mail: diegomorenosud@hotmail.com

Received: May. 18, 2021

Revised: May. 22, 2021

Accepted: May. 26, 2021

Published online: May. 27, 2021

(c) It is identical to the Creative Commons Attribution Non-Commercial License (http://creativecommons.org/licenses/by-nc/4.0/). vision, risk of thrombosis, fluid retention, etc. During this pandemic, we have observed an inappropriate use of dexamethasone in patients with COVID-19 who do not require oxygen therapy or who are during the first 7 days of illness. So, many patients including young patients without comorbidities come to the emergency room with severe COVID-19 and with a higher risk of mortality. Therefore, we as well as Bahl et al. propose prescribing corticosteroids to patients with mechanical ventilation, patients 72 hours after being hospitalized, or patients with $>7$ days of illness and requiring oxygen therapy. This latter group would benefit the most from the use of dexamethasone in the first 24 hours of oxygen therapy, as suggested by Lee et al. ${ }^{1}$

Factors associated with the incorrect use of dexamethasone include inadequate medical training in the management of patients with COVID-19. Due to the fast increase in the number of cases of patients with COVID-19, many patients are afraid of going to be treated in hospitals due to being infected with COVID-19, or they are not being hospitalized due to lack of available hospital beds or oxygen; thus, many people are cared at home by private doctors who prescribe corticosteroids at inappropriate stages of the disease and are not guided by evidence-based medicine. Another factor is self-medication. In Peru, the sale of drugs without a doctor's prescription is very frequent $(56.6 \%-87.8 \%)^{4,5}$; the prescription is often made by nonmedical professionals, such as pharmaceutical technicians, technical nurses, or nurses.

Therefore, it is essential the appropriate time when to use dexamethasone, adequate capacitation of the medical staff, and the intervention of government health regulatory entities to avoid the sale of drugs without a medical prescription.

\section{Authors' Contributions}

Writing - original draft preparation: Marreros DMM, Moreno MLA, Gil KGT. Writing - review and editing: Guzman CM. Approval of final manuscript: all authors. 


\section{Conflicts of Interest}

No potential conflict of interest relevant to this article was reported.

\section{Funding}

No funding to declare.

\section{References}

1. Lee HW, Park J, Lee JK, Park TY, Heo EY. The effect of the timing of dexamethasone administration in patients with COVID-19 pneumonia. Tuberc Respir Dis 2021 Mar 29 [Epub]. https://doi.org/10.4046/trd.2021.0309.

2. RECOVERY Collaborative Group; Lim WS, Emberson JR, Mafham M, Bell JL, Linsell L, et al. Dexamethasone in hospitalized patients with Covid-19. N Engl J Med 2021;384:693704.

3. Bahl A, Johnson S, Chen NW. Timing of corticosteroids impacts mortality in hospitalized COVID-19 patients. Int Emerg Med 2021 Feb 5 [Epub]. https://doi.org/10.1007/s11739-02102655-6.

4. Medina ML, Dominguez KC. Self-medication in adults attending the drugstores of the Jesús Nazareno District, Ayacucho 2015. An Fac Med 2016;77:387-92.

5. Hermoza-Moquillaza R, Loza-Munarriz C, Rodríguez-Hurtada D, Arellano-Sacramento C, Hermoza-Moquillaza V. Selfmedication in district of Lima Metropolitan, Peru. Rev Med Hered 2016;27:15-21. 